\title{
Possibilities of using 3D printing for surface layers
}

\author{
Agnieszka Dulska ${ }^{1, *}$ \\ ${ }^{1}$ Silesian University of Technology, Department of Foundry Engineering, Towarowa St. 7, 44-100 \\ Gliwice, Poland
}

\begin{abstract}
This article describes how to improve the tribological properties of cast iron by local strengthening by titanium layer, directly in the casting process. The research comprised test molds with a titanium (composite) layer. The insert with titanium was made basing on proprietary development of geometric assumptions. The innovation relies on application the 3D printing insert obtaining in SLM (selective laser melting) method. The tests included measurement of resistance to abrasive wear and carried out metallographic, microhardness measurements as the presents detailed geometry of the insert as well. On the basis of obtaining results was stated that there is a possibility of reinforcing surface layer of the grey cast iron casting by using $3 \mathrm{D}$ printing scaffold insert in the method of mould cavity preparation. Moreover there was a local increase in hardness and abrasive wear resistance in spite of the precipitation of titanium carbides in surface layer of grey cast iron.
\end{abstract}

\section{Introduction}

The market requirements affecting the development of industry in the world are constantly growing, what increases the demand for new, better production technologies. The quality and durability of machine components or structures must also be improved. Traditional materials are increasingly unable to meet the technological requirements. Increasing interest around surface layers and elements reinforced with the core caused their very dynamic developement. Improving the usable properties, extending the life of tools and subassemblies, and also reducing the production time and production costs are just a few of the advantages of using surface layers [1-4].

One of the methods of obtaining the surface layers is pouring a liquid metal into the mold with the perform (insert, cover) inside. This is a casting method for obtaining surface layers. After pouring the liquid metal into the mould, the covering create a layer on the surface of the cast. The processes which take a place inside the mold cause the creation of a cast with a permanent combination of two chemically different materials with different properties. The big advantage of using this method is that the obtained layer is created in the one process - casting, and the technology does not differ from the production of castings - it requires only pre-preparation of the insert (preform) [1-7].

\footnotetext{
*Corresponding author: agnieszka.dulska@polsl.pl
} 
The methods of preparing the mould:

- layers formed as a result of pouring by liquid metal the inserts into the mold (for example: bimetals),

- layers obtained by melted the alloy components on the mold surface by the heat of the poured liquid metal,

- $\quad$ grained layers created by infiltration of a liquid metal into a layer formed on a mold.

- The preform should have appropriate properties such as:

- $\quad$ adequate wettability,

- melting temperature lower than the melting temperature of the base material,

- a certain thickness,

- non-gaseous binder material.

The inserts used to create the surface layers most often consist of alloy components such as: $\mathrm{Cr}, \mathrm{Ni}, \mathrm{Co}, \mathrm{Fe}-\mathrm{Cr}, \mathrm{Fe}-\mathrm{Mn}, \mathrm{Fe}-\mathrm{W}, \mathrm{Fe}-\mathrm{Mo}$, as well as binders formed from surface-active compounds $[1,3,4]$.

A new way to prepare inserts for the production of surface layers is the $3 \mathrm{D}$ printing method. It allows to produce inserts with a complicated shape, fully recreating the shape of the place in the mold cavity, where higher properties, eg higher abrasion resistance are needed to obtain $[3,8-10]$.

\section{Methods and Materials}

The purpose of the research was to create an innovative material based on the cast iron with titanium reinforcement. The research included observation of the structure on the optical and scanning microscope as well as the measurement the microhardness and abrasion resistance.

The gray eutectic cast iron (base cast) and the insert made of titanium alloy (working part) were used to make the composite cast. The modular insert $(50 \times 15 \times 15 \mathrm{~mm})$ was made using the method of 3D printing in the process of Selective Laser Melting (SLM) from titanium alloy (TiAl6V4 - table 1).

Table 1. Chemical content of the alloy TiAl16V4.

\begin{tabular}{|l|l|l|l|l|l|l|l|}
\hline Element & $\mathrm{Fe}$ & $\mathrm{C}$ & $\mathrm{N}$ & $\mathrm{O}$ & $\mathrm{H}$ & $\mathrm{Al}$ & $\mathrm{V}$ \\
\hline Content $[\%]$ & $\leq 0,30$ & $\leq 0,08$ & $\leq 0,05$ & $\leq 0,20$ & $\leq 0,015$ & $5,5-6,75$ & $3,5-4,5$ \\
\hline
\end{tabular}

A modular insert with a geometrical form of elementary cells (Fig. 1a) was designed and printed. The cell is formed by a circular section connectors that combined in the nodes. In this way, elementary cells in the shape of a regular body (cube) were obtained. The single cell model is shown in the Figure $1 \mathrm{~b}$ and $1 \mathrm{c}$. The distance between individual nodes is $2 \mathrm{~mm}$, the diameter of the connector is $1.5 \mathrm{~mm}$. In addition, the inside diameter of the connector was set at 1 and $0 \mathrm{~mm}$, depends on the connector :"empty" or "full" (Fig. 1b and 1c). The shape of the cast with the place of location of the insert is shown in Figure 2.

a)

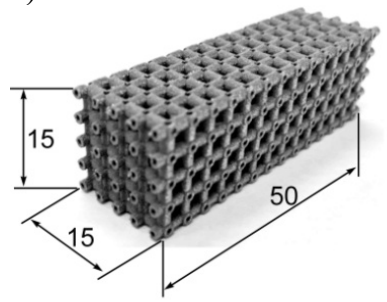

b)

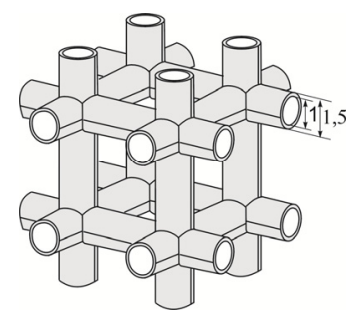

c)

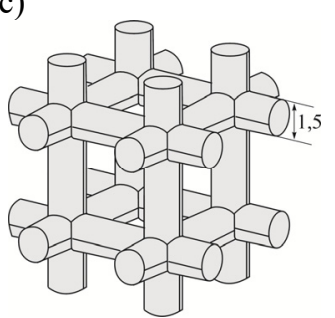

Fig. 1. 3D model of a titanium insert; a) a real insert; b) an insert with an empty connector; c) an insert with a full connector. 


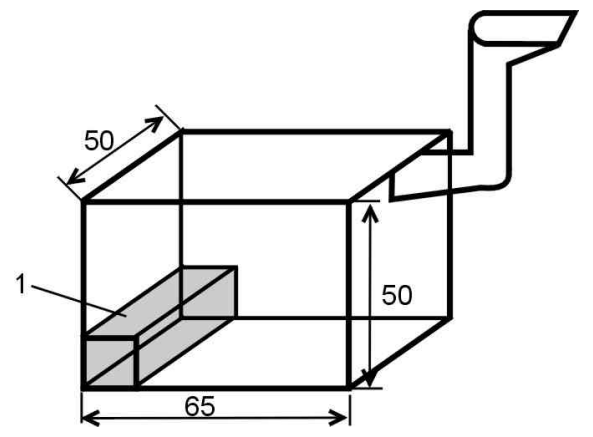

Fig. 2. The shape of the cast with dimensions; 1 - modular insert.

\section{Results of the research}

The research included observation of the structure of the materials connection on the optical and scanning microscope as well as the measurement of the microhardness and abrasion resistance.

Metallographic examinations of the resulting layer were performed on a microscope Nikon Eclipse LV $150 \mathrm{~N}$ (fig. 3) to determine the type of connection in the structure. The result of combining the two materials was a layer of gray cast iron and titanium reinforcement (with many carbide precipitates). The formed carbides have an irregular and different shape, different size, and their concentration is highest at the place of dissolution of the insert.
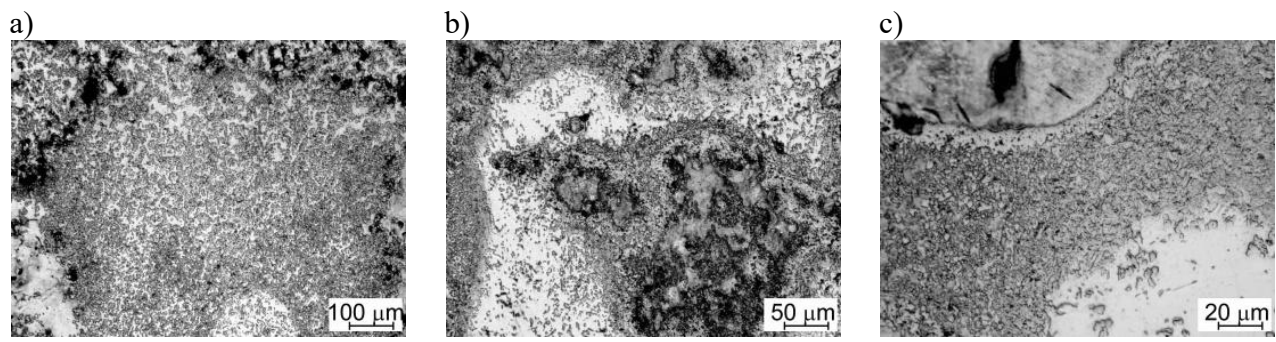

Fig. 3. Areas of Titanium carbides precipitates: a) zoom 100x; b) zoom 200x; c) zoom 500x.

The pictures from the Phenom scanning microscope are presented in Figure 4. Determining the approximate size of the precipitated titanium carbides, which ranged from 1.5 to $6 \mu \mathrm{m}$ was based on the pictures from the microscope. Figures $4 \mathrm{a}$ and $4 \mathrm{~b}$ present different concentration zones of the carbides. The concentration zones depend mainly on the distance from the skeletal insert - closer to the insert the concentration is bigger.

Additionally, Figure $4 \mathrm{c}$ shows photos of the breakthrough of the sample, on which the shape of carbide precipitates is visible.

The research included also the point analysis of chemical composition. The purpose of this examination was to determine the elements occurring in the structure of the resulting material (Figure 5).

The microhardness test were executed on the hardness tester FUTURE TECH FM-700 with a load $1000 \mathrm{~g}$. The testing area included zones with significant concentrations of titanium carbide precipitates. Figure 6 shows an example of a measurement place and obtained results of microhardness.

Diversified values of microhardness measurements are caused of inhomogeneous concentration of carbides, therefore it can be concluded that a higher measurement value means a higher concentration of carbides. At very low values, it can be concluded that the 
measurement covered a larger part of the warp of the material than the carbides. It was noted that the results of the warp measurement were slightly higher than for typical gray cast iron. Therefore, the warp was strengthened not only in the place of the material connection, but in the region of the precipitations. The results were compared with materials exposed to abrasive wear (table 2) and presented in table 3.

a)

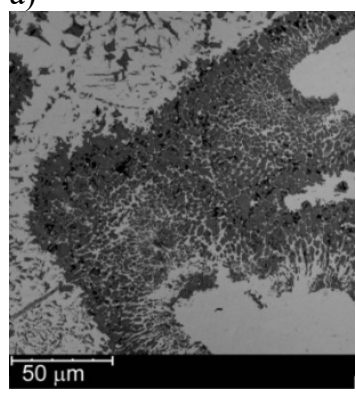

b)

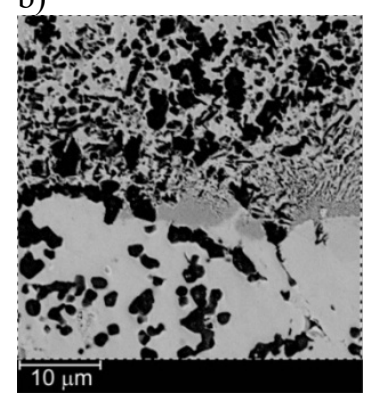

c)

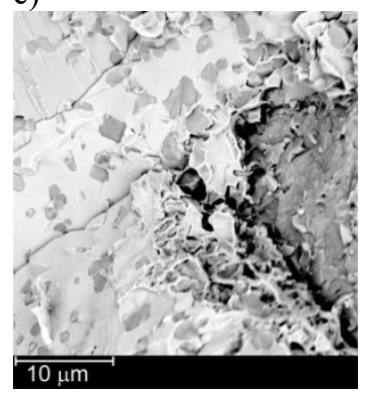

Fig. 4. Microstructure of the surface layer; a), b) upper view; c) breakthrough.

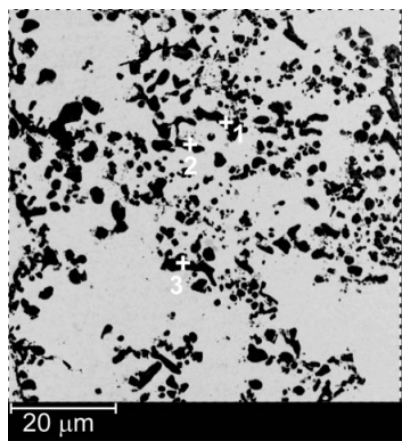

\begin{tabular}{|c|l|l|l|}
\hline Test & Ti\% & $\mathbf{C \%}$ & $\mathbf{F e} \%$ \\
\hline 1 & 72,1 & 21,4 & 6,5 \\
\hline 2 & 71 & 21,9 & 7,1 \\
\hline 3 & 71 & 22,8 & 6,3 \\
\hline
\end{tabular}

Fig. 5. The point analysis of chemical composition.

a)

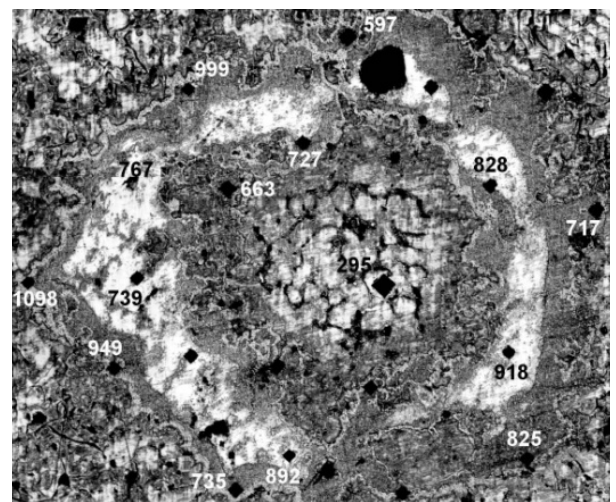

b)

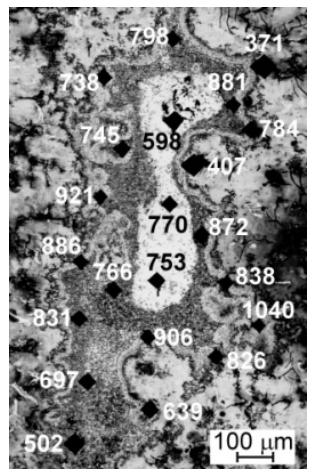

Fig. 6. The microhardness measurement area for the surface layer with an insert with a connector: a) empty; b) full.

Tabel 2. Chemical content of comparative materials.

\begin{tabular}{|c|c|c|c|c|c|c|}
\hline Material & C [\%] & Mn [\%] & Si [\%] & Cr [\%] & Ni [\%] & Mo [\%] \\
\hline High-chromium cast iron & 2,85 & 0,385 & 0,657 & 20,4 & 1,48 & 0,565 \\
\hline Low-alloy steel & 0,22 & 1,09 & 0,75 & 0,65 & 0,296 & 0,25 \\
\hline GJL-250 & $3,00-3,25$ & $0,40-0,70$ & $1,85-2,10$ & - & - & - \\
\hline
\end{tabular}


The obtained surface layers were tested to abrasion resistance. The test device consists of a table on which the counter-sample is mounted, the motor generating the rotary motion and the arm which generates a reciprocating movement of the sample on the surface of the counter-sample. The device allows to use different values of a load by using weights of a given mass. The silicon carbide abrasive paper ( $\mathrm{SiC})$ with a granularity of P50 was used in each of the tests. The grinding cycles were carried out with a load of $10 \mathrm{~kg}$. One measurement consisted of 2,500 repetitions (ie $500 \mathrm{~m}$ ). Four measurements were made for each of the samples. The exact loss of material was determined by weighing the sample before and after each measurement. Average losses in mass are showed in Table 4.

Tabel 3. Average value of the microhardness test for materials ( $\mathrm{Sm}$ - average value of the microhardness).

\begin{tabular}{|l|c|c|c|c|c|c|c|c|c|}
\hline Test number & $\mathbf{1}$ & $\mathbf{2}$ & $\mathbf{3}$ & $\mathbf{4}$ & $\mathbf{5}$ & $\mathbf{6}$ & $\mathbf{7}$ & $\mathbf{8}$ & $\mathbf{S}_{\mathbf{m}}$ \\
\hline High-chromium cast iron & 463 & 459 & 540 & 450 & 449 & 506 & 410 & 558 & $\mathbf{4 7 9}$ \\
\hline Low-alloy steel & 594 & 559 & 753 & 524 & 623 & 590 & 655 & 713 & $\mathbf{6 2 6}$ \\
\hline Gray cast iron, base cast & 308 & 295 & 329 & 324 & 318 & 283 & 321 & 333 & $\mathbf{3 1 4}$ \\
\hline
\end{tabular}

Tabel 4. Losses of the materials under the load $10 \mathrm{~kg} / 10 \mathrm{~cm}^{2}$.

\begin{tabular}{|c|c|c|c|}
\hline & Test number & Weight [g] & Loss [g] \\
\hline \multirow{5}{*}{$\begin{array}{l}\text { Titanium layer - } \\
\text { empty connector } \\
\text { number } 1\end{array}$} & 0 & 192,437 & ----- \\
\hline & 1 & 191,880 & 0,557 \\
\hline & 2 & 191,459 & 0,421 \\
\hline & 3 & 190,916 & 0,543 \\
\hline & 4 & 190,470 & 0,446 \\
\hline \multicolumn{3}{|l|}{ Average } & 0,492 \\
\hline \multirow{5}{*}{$\begin{array}{l}\text { Titanium layer - } \\
\text { empty connector } \\
\text { number } 2\end{array}$} & 0 & 191,088 & ---- \\
\hline & 1 & 190,960 & 0,128 \\
\hline & 2 & 190,844 & 0,116 \\
\hline & 3 & 190,736 & 0,108 \\
\hline & 4 & 190,621 & 0,115 \\
\hline \multicolumn{3}{|l|}{ Average } & 0,117 \\
\hline \multirow{5}{*}{$\begin{array}{l}\text { Titanium layer - full } \\
\text { connector }\end{array}$} & 0 & 187,871 & ---- \\
\hline & 1 & 187,746 & 0,125 \\
\hline & 2 & 187,663 & 0,083 \\
\hline & 3 & 187,580 & 0,083 \\
\hline & 4 & 187,497 & 0,083 \\
\hline \multicolumn{3}{|l|}{ Average } & 0,094 \\
\hline
\end{tabular}

The obtained results were compared with measurements for higher abrasion resistanced materials (high-chromium cast iron) and a base material (gray cast iron GJL-250). The tested alloys were characterized by the chemical composition shown in Table 2 and abrasion resistance presented in Table 5. Tests made for the reference materials were carried out under the same conditions as cast iron castings with a titanium insert.

Tabel 5. The results of the abrasion resistance test under the load $1 \mathrm{~kg} / 1 \mathrm{~cm}^{2}$.

\begin{tabular}{|l|l|}
\hline Sample & Average loss $\mathbf{~ g ]}]$ \\
\hline Titanium layer - empty connector number 1 & 0,049 \\
\hline Titanium layer - empty connector number 2 & 0,012 \\
\hline Titanium layer - full connector & 0,009 \\
\hline High-chromium cast iron & 0,018 \\
\hline GJL-250 & 0,221 \\
\hline
\end{tabular}


Comparing the results, it was found that the use of 3D printed titanium alloy inserts greatly increases abrasion resistance in comparing to the "base" material - gray cast iron GJL-250. Compared to high-chromium cast iron, the weight loss value is comparable. However, the main advantage of the tested castings with a titanium layer is the possibility of reinforcing only in a place exposed to wear (local reinforcement) and not as in the case of chromium cast iron - in the entire volume. The largest loss in mass was observed in the tested sample No. 1 (casting with a titanium insert, empty connector). It probably means that local melting of the insert appeared (too high pouring temperature).

\section{Conclusions}

The inserts used during the research were made using the SLM method. The advantage of these inserts is that they can be produce in the shape of a flat skeleton or any shape corresponding to the work surface of the cast part (machine).

The conclusions were made on the basis of the conducted research:

1. It is possible to strengthen the surface layer of a gray cast iron casting using a modular insert printed in the SLM method.

2. As a result of the reaction between the insert (TiAl6V4) and the metal (gray cast iron) locally numerous carbides (mainly TiC) were created. Carbides guarantee the increase of hardness and resistance to abrasive wear.

3. The functional properties depend mainly on the size of the insert (the internal dimensions of the connector) and on the temperature of the pouring the liquid metal into the mold.

\section{References}

[1] T. Wróbel, Archives of Materials Science and Engineering, 48(2) (2011)

[2] M. Dojka, R. Dojka, A. Studnicki, Archives of Foundry Engineering, 17(1) 37-40 (2017)

[3] N. Przyszlak, A. Dulska, T. Wróbel, J. Szajnar, Archives of Foundry Engineering 18(1), 99-102 (2018)

[4] A. Dulska, A. Studnicki, J. Szajnar, Archives of Metallurgy and Materials, 62(1), 365367 (2017)

[5] E. Çalikoğlu, M. Çetin, Production of bi-metal material, Materials of International Iron and Steel Symposium (Karabük, Turkey, 156-161, 2012)

[6] S. Ertürk, O. Çakir, L. Kumruoglu, A. Ozel, Acta Physica Polonica A, 125(2), 452453 (2013).

[7] P. Jonšta, P. Váňová, S. Brožová, P. Pustějovská, J. Sojka, Z. Jonšta, M. Ingaldi, Archives of Metallurgy and Materials, 61(2), 709-711 (2016)

[8] M. Cholewa, M. Dziuba-Kałuża, Archives of Foundry Engineering, 9(3), 29-34 (2009)

[9] M. Król, T. Tański, Archives of Metallurgy and Materials, 61(3), 1291-1296 (2016)

[10] Patent Application No. P.417657 